\title{
Work-Family Conflict in Nursing: The Role of Work Schedules, Familial Antecedents and Emotional Regulation
}

\author{
Claudia Gonnelli, Mirian Agus, Rosalba Raffagnino \\ University of Florence, Florence, Italy \\ Email: rosalba.raffagnino@unifi.it
}

How to cite this paper: Gonnelli, C., Agus, M. and Raffagnino, R. (2018) Work-Family Conflict in Nursing: The Role of Work Schedules, Familial Antecedents and Emotional Regulation. Open Journal of Medical Psychology, 7, 123-147.

https://doi.org/10.4236/ojmp.2018.74010

Received: September 6, 2018

Accepted: October 19, 2018

Published: October 22, 2018

Copyright (e) 2018 by authors and Scientific Research Publishing Inc. This work is licensed under the Creative Commons Attribution International License (CC BY 4.0).

http://creativecommons.org/licenses/by/4.0/

\begin{abstract}
This paper explores the influences of Emotional Regulation (ER) and work schedules on work-family conflict (WFC) among Italian nurses, also accounting for some familial variables. The data used in this study come from a survey conducted on 191 nurses working in two public hospitals of Tuscany (Italy). Stepwise multiple regressions were applied to examine the relationships among these variables, using the WFC as dependent variable. We found that some work related dimensions had direct effects on WFC outcomes; however, these impacts on the criterion variables are modified by the effects exerted by specific ER strategies.
\end{abstract}

\section{Keywords}

Work Family Conflict, Emotion Regulation, Work Schedule, Familial Status, Familial Support

\section{Introduction}

Nursing is considered a complex profession which, despite being a fulfilling and satisfying job [1], can be impaired by many different stressful situations that have costs in terms of productivity, satisfaction, patients' safety, nurses' physical and mental health, stress, burnout and turnover [2] [3]. In fact, nurses are faced with many different critical challenges regarding both structural-job tasks, work hours-and psychosocial demands-relationships and interactions-, which can influence their performance as well as their health and well-being [4] [5]. In recent years, researchers and practitioners have outlined the role of work-family conflict (WFC), acknowledged by the literature about work as a risk factor of workers' productivity, health and well-being. While WF interface lite- 
rature has made considerable progress and much is now known about the antecedents and consequences of WFC in various different occupational sectors [6], knowledge about these topics in nursing is still relatively under-researched. Several noteworthy gaps remain to explore, even if some scholars have already recognized the importance of WF interface for the nursing profession, both for its effects on the nursing shortage and performance [7]. Among these gaps is the analysis of those variables that may increase or decrease the effects of the different antecedents on WFC, such as affective and emotional dimensions. WF interface has proved that, while negative affective responses can be associated with increased WFC [8], the people's ability to perceive, understand and manage their emotions-especially their emotional intelligence-would help them to balance the work-family life [9]. The role of emotions and emotional skills is further stressed in jobs like nursing, in which workers have to face various interpersonal, social, relational and emotional situations. In fact, in order to address their job challenges in an adequate and functional way, their emotional skills (as Emotional Intelligence/EI) are crucial to improve their performance and job satisfaction, as well as to reduce job stress and burnout [10] [11]. These skills are also considered key individual resources to balance work and family domains [12]. The construct of emotional labor has been used as general, theoretical grounding: it refers to emotional expressions related to job and family display rules, as well as to roles' expectations. Thus, it has been considered as an emotional regulatory process [8].

In spite of the growing interest in this topic and the fact that most nursing literature outlined the outcomes of EI on nurses' performance [11], we know little about the role of ER ability in buffering the effects of work and family antecedents on the WFC. In particular, as far we know, no research provides any knowledge about the mediator role of the different ER strategies to help or hinder this interface between work and family domains.

In our research, we aim to narrow this gap by empirically analyzing the direct effect of ER on WFC, and proposing ER as a bridge among work and family dimensions. In these conditions, the ERs dimensions might become specific risks or protective factors influencing the WFC. This investigation permits to add knowledge and fully explains the features of WFC in nurses by examining within-individual dimensions, unlike most research, which considers contextual and between-individual differences.

\section{Background}

\subsection{Work-Family Conflict}

Within the framework of the WF interface, analyzed as a spillover mechanism regarding the flow of attitudes, emotions and behaviours from one life domain into the other [13], the Work-Family Conflict (WFC) focuses on the mutual incompatibility of the role pressures in both life domains [14]. Greenhaus and Beutell [14] declared its bidirectionality, distinguishing the Work-to-Family-Conflict 
(W-F-C), i.e. the difficulty lived at work affecting one's family functioning, from Family-to-Work conflict (F-W-C), that is those family problems affecting the functioning at work. The first direction is the most relevant, also in nursing, both in European [7] and extra-European countries [15]. Also, while women seem to be more vulnerable than men to the two directions of WFC, they nonetheless expressed greater levels of F-W-C compared to men [16]. Instead, men are more exposed to W-to-F conflict if they have experienced marital dissatisfaction, parental distress, and psychological and physical stress [17]. Besides, Keepnews, Brewer, Kovner and Shin [18] found a higher level of WFC among Generation X (nurses born between 1965 and 1979) than the other groups (Baby Boomers, born between 1946 and 1964 and Generation Y, born after 1980). In some cases, scholars took into account the different job health organizations in which nurses work. For Yamaguchi, Inoue, Harada and Oike [19] hospital nurses experienced significantly more W-F-C than home healthcare nurses or home nurses.

WFC can have several negative outcomes regarding the individual, familial and job dimensions. Nursing literature reports its negative connection with job satisfaction, job performance, psychological health and well-being [20] and its positive effects on physical health problems [21], burnout [22], and with turnover [19]. In some cases, in nursing, the WFC outcomes are not direct, but mediated by other variables, such as job satisfaction, stress, and psychological features [20] [22].

Furthermore, scholars deepened the understanding of individual, relationship, familial, work and organizational factors which could be relevant antecedents (both in terms of risk, and of protective factors) of WFC. Greenhaus and Beutell [14] proposed three WFC antecedent types experienced in one of the two domains, which may influence the functions, performance, satisfaction, expectations and rules of the other one. They identify the time-based conflict, i.e. the time required by one of the two roles; the strain-based conflict, i.e. the experienced energy in term of negative emotional states and fatigue; and the behaviour-based conflict, i.e. the required behaviours, expectations, or rules, experienced in one role but influencing the results in the other. In the general WF literature, scholars mainly focused on the time-based conflict, paying particular attention to working hours and their interference with the time available for family and leisure [23] [24], and increasing couple conflict [25]. In nursing, attention to the time is particularly important as this job involves different and often inconvenient work schedules, like evening work, night work, weekend work, and shift work. A consistent number of studies focused on the question of how the length of working hours affects WFC [26] [27] [28]. However, focusing on full and part-time working, Abrahamsen, Holte and Laine [29] showed that in both cases nurses expressed similar levels of WF interference. Also inconvenient work schedules-evening work, night work, weekend work, shift work (shift and night work, evening shift, rotating shifts), variable/flexible working time, pro- 
longed duty periods-had been considered as important antecedents of WFC [30] [31]. In Italy, Camerino et al. [32] found that quantitative workload, together with the performance of tasks not belonging to the nursing profession, and the number of weekends/month spent at work, were all strongly associated with WFC. In the family domain, scholars considered that familial demands like housework and childcare can create difficulties in managing familial and job time. Takeuchi and Yamazaki [28] found that WFC increase if nurses do not receive assistance with housework during workdays, and thus spend much time in housework and childcare.

The second type of antecedent identified by Greenhaus and Beutell [14] is strain-based conflict. WF literature has mainly inspected it in consideration of the negative effects of job-stress on marital interaction and marital quality [33], and of the perceived parenting stress and parenting self-efficacy associated with WFC [34] [35]. In nursing, we also found an attention to job experience and in particular to job demands as workload and emotional dissonance. Workload (defined as the condition of having much work to do and little time to do it) has been associated with nurses' WFC [26]. Emotional dissonance, regarding the discrepancy between felt and displayed emotions [36], as well as emotional charge have been associated with WFC [26] [37]. Even problematic job relationships with supervisor and/or co-workers can be important for WFC; as a case in point one may consider supervisors' backlash (or the workers' perception that their supervisors oppose or resent their efforts to balance work and family domains) [26] and low support in the workplace [28]. In the familial domain, Lagerström et al. [27] found that inter-role problems were mainly experienced by nurses who had large families, young children, and family members with health problems; however, both married and unmarried female nurses reported heavy family obligations, as the unmarried usually live with their family and are also caregivers to their parents.

As far as the third type of WFC-i.e. behavioural-based conflict-is concerned, we found no reference in the literature about topics that are present in WF literature. For instance, specific research observes that high work role expectations, considering the work role as particularly relevant for workers' identity, and the responsibility for others required by the selfsame job, all are meaningful antecedents of WFC.

Other risk factors and some protective ones that may prevent or help persons cope effectively with WFC, have been identified. For instance, dispositional factors like self-efficacy, positive affect, internal locus of control, hope, optimism and resilience can reduce WFC [38] [39]. Takeuchi and Yamazaki [28] identified as a protective factor of WFC the sense of coherence (SOC)-regarded as a stress-coping ability-implying a positive attitude, which allows to live and to accept stressors as opportunities for personal growth. As observed by these authors, when SOC was low the WFC increased, and when it was present among the nurses it fostered a buffering effect against depression resulting from WFC. 
Factors regarding the work domain can also be considered important protective factors of WFC; among these, flexible work scheduling, clear boundaries around work (i.e., the workers do not work at home), the possibility to work from home, the social support of colleagues and supervisor, autonomy competence and relatedness [40] [41] [42]. Of the previously mentioned factors, social support has been analyzed more in depth. For Yildirim and Yacan [43] social support from the supervisor, including both instrumental (providing assistance and advice) and emotional support (emphatic understanding and sensitivity) to work-family issues, show a direct association with W-F-C. Then, in the family domain, Lagerström et al. [27] observed that interviewed nurses reported seeking familial support as an active response to work-family roles interference. In addition, emotional support by partner [44] and marital satisfaction [45] can help people cope with WFC. Regarding social support, Gandi [15] found some gender differences. In fact, the association of social support lack with home-work interference is stronger among men than among women. This association was then related to emotional exhaustion.

\subsection{Emotional Regulation}

Widely studied in psychological literature, and often mentioned in nursing as a specific dimension of the most assessed construct of emotional intelligence (EI) [46], Emotional Regulation (ER) regards the ability to manage one's own emotions and it "refers to shaping which emotions one has, when one has them, and how one experiences or expresses these emotions" ([47], p. 6). Scholars have recognized the relevance of this concept in understanding relational and interpersonal efficacy as well as the difficulties in the work context. From the ' 70 to the early '80, Hochschild [48] [49] drew the attention of research to the significance of managing emotion in the workplace; he also coined the terms "emotional labour" or "emotion work" to describe this work and proposed that regulation of emotion is essential for the effective functioning of organizations, particularly health organizations. Then, there was an increasing attention to ER processes as moderators among occupational stressors and well-being [50]. In nursing, this construct has been explored focusing mainly on the emotional nature of this job, in order to help nurses face and cope with emotional, stressful demands, to look at emotional labour, to recognize and respond to patients' emotions in an empathic way, and to have effective nurse-patient interactions [51] [52] [53].

The ER analysis has been carried out frequently with reference to the different ER strategies (ERS). In psychological literature, scholars have identified a wide repertoire of them, such as emotional avoidance, acceptance, awareness, the ability to understand and differentiate one's own emotions, reappraisal, expressive suppression, situation modification, sharing the feelings, seeking emotional support and so on [54] [55] [56]. According to Gross [57], some of these ERS are response-focused, thus addressed to the emotional response itself (as reappraisal); others, instead, come before the emotional response has been fully activated 
(as emotional suppression and avoidance). Schmidth and Diestel [5] match this distinction with the surface and deep acting in emotional labour, proposed in nursing literature. The former, involving the regulation of emotional expression, has been associated with response-focused emotional strategies; while the latter, regarding the change of the emotion state, has been linked to the strategies used before emotional expression.

As for ERS efficacy, psychological literature sustains the higher efficacy of response focused strategies-such as reappraisal-with respect to those applied before the response, as suppression of verbal or non-verbal emotional expression [58]. Likewise, in the working context, deep acting seems less detrimental to workers' health and well-being and their ability to face up to interpersonal stressors with respect to surface acting (for review, [59]).

Instead, this last has been associated with emotional exhaustion, depressive symptoms, absenteeism and job dissatisfaction [5], as well as with those behaviors that are not genuine, and may negatively influence interpersonal relations and, subsequently, workers' well-being and performance [60]. The different efficacy of the two acting types has been explained observing that surface acting required higher cognitive control resources with respect to engaging in deep acting [60]. Biron and van Veldhoven [61] found that emotional acceptance (a deep acting) required poor effort in the emotional regulation at present. Anyway, deep acting didn't always have positive effects on health or organizational consequences, job satisfaction and job performance [59] [62].

In addition to the efficacy of the various ERS, some scholars outlined also their flexible use, their adequacy to the social contexts and their cost/benefit in relation to the social and interpersonal contexts [58] [63]. When individuals show a flexible use of ER, they tend to live different emotional states, in order not to have fixity persisting and intrusive emotional state [64], but rather a gradual change from an emotional state to another, and no abrupt change associated with emotional liability [65]. Furthermore, they activate an emotional state appropriate to a live situation, in order not to have dissonant emotions with respect to the expectations and rules [66]. Instead, inadequate reactions to live contexts and social situations, emotional states that are not appropriate and expected in that occasion, and ineffective behaviors in relation to the pursuing objectives, can lead to dis-regulatory processes [64] [66].

In general, scholars distinguished adaptive from maladaptive ERS. While the former-such as emotional acceptance, emotional clarity, awareness and cognitive reappraisal-lead to beneficial outcomes regarding personal, interpersonal and social functioning [64] [67], maladaptive ERS produce harmful outcomes. For instance, emotional avoidance and suppression, self-criticism, ruminating, worrying were associated with declines in instrumental behavior, social support, poor social relationships, lower social functioning, and difficulties in problem solving [67] [68] [69]. The use of these strategies has been associated also with depression, anxiety, as well as eating and personality disorders [70] [71]. 
Emotion is a construct widely influenced by gender differences. In fact, scholars showed that men and women differ in their emotional experiences [72]. Gender differences are signaled also for ERS, albeit sometime the results are inconsistent. Women seem to use ERS more, and to ruminate more than men (for review, [73]); in addition, girls experience greater difficulties than boys in regulating their negative emotions [74].

\section{Aim, Research Questions and Hypotheses}

This study aims to find out if the work/familial organization and the ERS are related with the perception of W-F-C and F-W-C. Specifically, the purpose of this study was to inspect if in a sample of Italian nurses, the background aspects related to the classical socio-demographic variables, the work schedules and the familial factors might be related with the experiences of $\mathrm{W}-\mathrm{F}-\mathrm{C}$ and $\mathrm{F}-\mathrm{W}-\mathrm{C}$, regarding the dimensions of time-based, strain-based and behaviour-based conflicts.

Furthermore, on the base of literature, we suppose that these relationships between the socio-demographic and work/familial factors and the directions of WFC might be affected by the role of individual ERS. In particular, we assume that the effects of work and familial antecedents on WFC enhanced nurses' use of weak ER strategies and that, on the other hand, these effects could be buffered by effective ER strategies. If, as in Lazarus and Folkman [75] cognitive appraisal theory, the perception of emotional factors can be influenced by the self-assessment of potentially threatening situations, then nurses with good ER should perceive work-family interference as a minor threat with respect to nurses with poor ER, because the former are aware of having good emotional coping resources.

The effects of ER dysfunctions on W-F-C and F-W-C have often been overlooked in the context of Italian nurses. Indeed, the literature outlined some associations among socio-demographic variables, emotional demands and $\mathrm{W}-\mathrm{F}-\mathrm{C} / \mathrm{F}-\mathrm{W}-\mathrm{C}$, but, at the best of our knowledge, there are no studies assessing the multivariate relationships among these dimensions in a multidimensional research design. Therefore, we aim to assess these associations adopting an integrate research design in a sample of Italian nurses, in order to investigate the variables that potentially might serve as risk factors or as protective factors concerning the $\mathrm{W}-\mathrm{F}-/ \mathrm{F}-\mathrm{W}$-conflicts. In particular, we focus on some variables that scholars have identified as key risk and protective factors of WFC. So, we analyzed the potential effects of job category (registered nurses, social health operator), job years, work demands, working hours, work schedules (regular night work), shiftwork (with hours changing regularly between night, evening and day shifts), familial situation (relational status, having children, familial support) and demographic variables (gender, age), in relation to WFC dimensions (time based conflict, strain based conflict and behavior bases conflict), assumed as a 
dependent variable. The relationships among work/familial related factors, socio-personal dimensions, and WFC were assessed considering and controlling the potential role of ER dimensions, which may exert a significant effect on our criterion variables.

Regarding these aspects, we posed the following questions:

1) Are there any differences in the means of ER and WFC in relation to the socio-personal, familial and organizational dimensions?

2) What variables might be considered as risk/protective factors in relation to the perception of $W-F-/ F-W$-conflicts?

Specifically:

i) What is the influence of different ERS on $W$ - $F$ - and $F-W$-conflicts?

ii) Are the effective ER strategies associated with less $W-F-/ F-W$-conflicts?

In general, as the purpose of this article is to extend the knowledge of the association between dispositions and WFC, we combine two areas of interest in nursing literature: ER and WFC.

\section{Methods}

\subsection{Participants and Procedure}

191 Italian nurses were involved in the study (mean age $=43.80=$; sd age $=9.17$ ); the majority of participants were females (73.8\%). $75.4 \%$ of them were married or cohabiting; their actual relationship lasted on average 16.31 years $(\mathrm{sd}=10.32)$, having 1.51 children $(\mathrm{sd}=2.78)$.

The participants worked in two Tuscan hospitals; the mean of their seniority of work was 18.08 years $(s d=9.56)$; their work schedule was on average 8.21 hours per day $(s d=1.72) .41 .4 \%$ of participants were graduated; $45 \%$ had attended high school.

The collection of data took place between January and July 2016. Thanks to the collaboration of ward sisters, about 1000 questionnaires were distributed in the various wards of the two hospitals (non-probabilistic sampling). The protocol of research was fulfilled in Italian and included a letter describing the aim of the study (assuring anonymity and confidentiality), as well as instructions to fulfill the survey. The survey was not mandatory and participation was related to the nurses' determination of join the research (the participants did not have any benefit to join the research).The study protocol was approved by the superintendent of the Health Care Structures, who then informed ward sisters about the research objectives and distributed the questionnaire. To guarantee confidentiality, responses were matched using anonymous codes provided by the participants. After compilation, all participants delivered their questionnaire in a sealed envelope so as to provide anonymity. The study was conducted in accordance with the guidelines for the ethical treatment of human participants of the Italian Psychological Association. Of the nearly 1000 surveys distributed, 250 were returned (response rate $=25 \%$ ), 59 of these were rejected for being incomplete. 


\subsection{Measures}

The first session of protocol assessed background information (age, gender, marital status, education, number of children, age of children). Other questions investigated the work features (work time pattern, variability of working time, working hours per day).

In order to assess ER, the Difficulties in Emotion Regulation Scale (DERS) [54] was administered, in its Italian version [76]. This instrument has 36 items, with 5 points Likert Scale (from 1-almost never to 5-almost always), assessing the levels of ER in relation to six domains (Non Acceptance, Goals, Impulse, Awareness, Strategies, Clarity). Its reliability is as good (Alpha $=0.93$ ) as its validity. Coherently with the authors' indications, the subscale scores were obtained by summing up the items related to each dimension.

A following section enclosed the Work Family Conflict Scale (WFCS) [77]: a multidimensional measure of perceived conflict between work and family assessed by 18 items (Likert Scale, from 0 - strongly disagree to 4-strongly agree). The participants were administered the Italian version of this scale [78]. The items referred to three dimensions: time-based, strain-based and behaviour-based. Each dimension was examined in relation to the bidirectional influence between family and work (the effect of "family on work", the effect of "work on family"); in this way, six different measurements of the dimensions of conflict were obtained. For each dimension, the reliability was higher than .70. Consistently with what suggested by Carlson et al. [77], the subscale scores were achieved adding the scores for the items inquiring the dimensions.

\section{Analytic Plan}

The data analysis was conducted, according to the type of the variable and if assumptions are met. Firstly, the univariate descriptive statistics were computed; in the following step the Bivariate Linear correlations (Pearson's r) were assessed in order to explore the linear relationships between the inquired dimensions (see Table 1). Subsequently, in order to evaluate the potential differences among means in the inquired dimensions of DERS and WFC in relation to socio-demographic and familial/working variables, two MANCOVA were performed. Finally, Multivariate Linear Regressions (through a stepwise method) were carried out, in which each dimension of WFC was used as criterion variable (six different regressions were applied). In these models, the socio-demographic, familial and organizational variables were inserted as predictors during the first step, and the dimensions of emotion regulation (DERS) during the second step. These analyses allow us to investigate the effect exerted by aforementioned predictors on the work-family and family-work conflict dimensions, in order to find the combination of predictors that maximizes the accuracy of prediction of criterion variable. These statistical procedures allow us to examine the significance of $\mathrm{R}^{2}$ change (explained as variance of criterion variable), in relation to each predictor's entry in the equation of regression. 


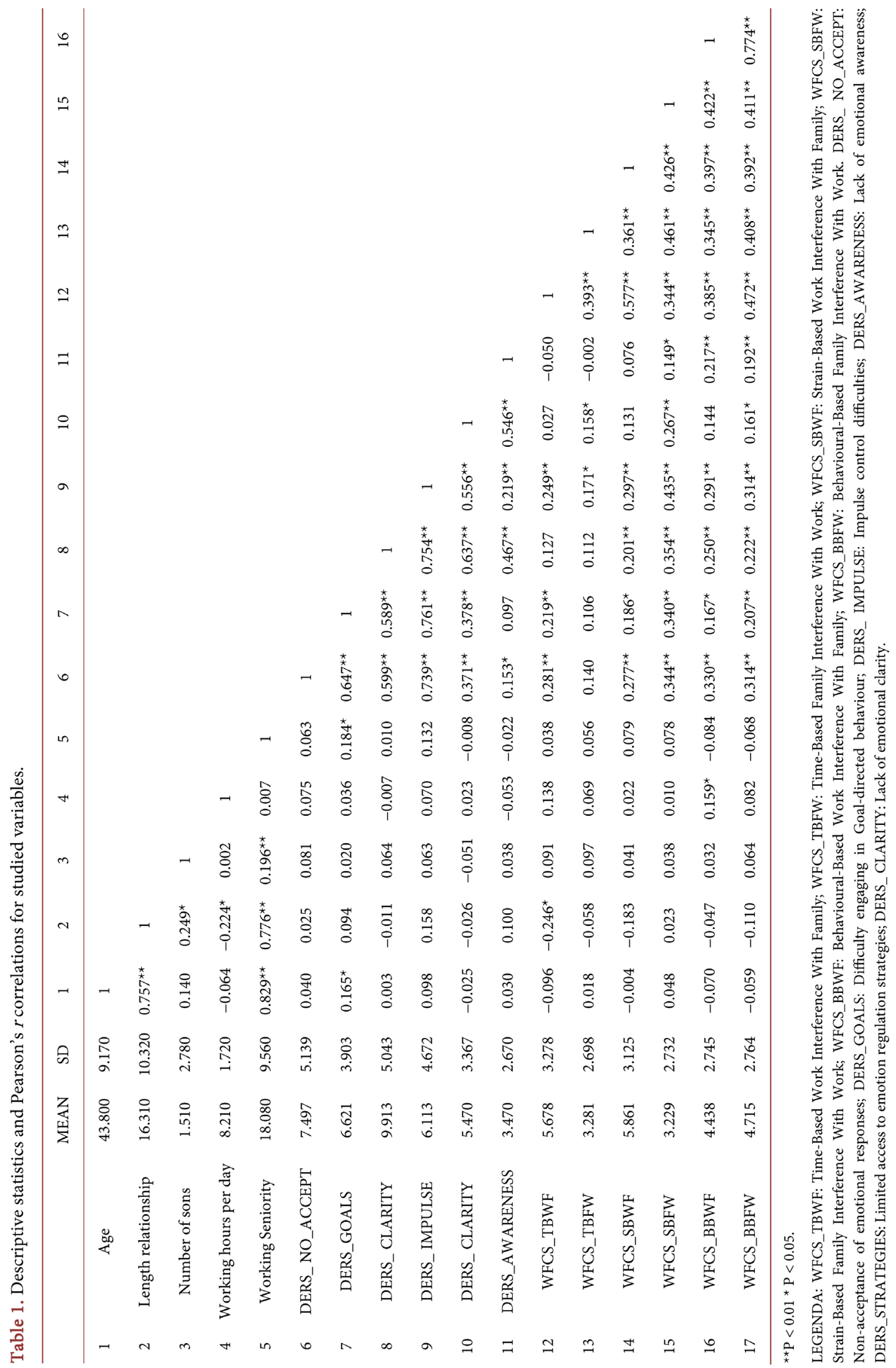




\section{Results}

Pearson's linear correlations showed that age only has a positive and significant correlation with the length of relationship $\left(r=0.757^{\star *}\right)$ and with working seniority $\left(r=0.829^{* *}\right)$. A positive correlation between age and DERS_GOALS $(r=$ $0.165^{*}$ ) can also be observed (see Table 1 ). The length of relationship has a positive and significant correlation with the number of children $\left(r=0.249^{*}\right)$, and a negative significant linear relation with the working hours per day $\left(r=-0.224^{*}\right)$; furthermore, it is positively correlated also with working seniority $\left(r=0.776^{* *}\right)$. The length of relationship is negatively related with the wfcs_tbwf (time-based work family interface) $\left(\mathrm{r}=-0.246^{*}\right)$. The number of children is positively correlated with the working seniority $\left(\mathrm{r}=0.196^{* *}\right)$. The variable working hours per day is correlated with wfcs_bbwf (Behavioural-Based Work Interference with Family) $\left(r=0.159^{\star}\right)$. The working seniority is positively correlated with DERS_GOALS $\left(\mathrm{r}=0.184^{*}\right)$.

Generally, the DERS_NO_ACCEPT is positively and significantly correlated with all other scales of DERS and WFCS, but not with WFCS_TBFW (time-based family work interface). Generally, we could observe a significant positive correlation between all the scales of DERS and WFCS, as reported in Table 1. Only the scale WFCS_TBFW showed few correlations with other dimensions, specifically with DERS_Impulse and DERS_Clarity; furthermore, it showed a significant and positive correlation with WFCS_TBWF. In sum, the scale of Clarity highlighted the lower levels of correlations with the WFCS among all DERS dimensions (see Table 1).

In order to focus on potential differences among participants' groups in relation to socio-demographic and organizational variables, the Mancovas were applied. Specifically, two Multivariate Analyses of Covariance were carried out, using the dimensions of the WFC and of the DERS respectively as dependent variables, with gender, the presence of children, the presence of family support as factors (design $2^{\star} 2^{\star} 2$ ), and the variables of age and the working hours per day as covariates (Table 2). It was observed that, although there are some significant effects in the multivariate level for the DERS dimensions, any statistically significant effect highlighted is in the univariate effects. Moreover, in the Mancova applied in relation to the WFCS scales, there are no significant differences among the means in relation to the covariates and factors examined (Table 2).

These findings allow us to speculate that our nurses' sample might be considered homogeneous in DERS and WFC across the groups identified and in relation to the investigated factors (gender, the presence of children, and of family support) controlling the effects of covariates (age and the working hours per day).

Subsequently, in order to assess the effect of socio-demographic variables, organizational and familial variables and emotion regulation strategies on the perceived conflict between family and work, Stepwise Multiple Regression Analyses were carried out on the data, in order to gather significant aspects in the prediction 
Table 2. Results of Mancovas for WFCS and DERS (multivariate tests), using gender, presence of children, presence of family support as factors $\left(2^{\star} 2^{\star} 2\right)$, using age and working hours per day as covariates.

Dependent variables: WFCS subscales

\begin{tabular}{|c|c|c|c|c|}
\hline Source & Wilks' Lambda & $F(d f=6 ; 159)$ & $p$ & $E t a^{2}$ \\
\hline age (covariate) & 0.986 & 0.372 & 0.896 & 0.014 \\
\hline working hour (covariate) & 0.943 & 1.626 & 0.143 & 0.057 \\
\hline \multicolumn{5}{|l|}{ Factors } \\
\hline gender & 0.974 & 0.724 & 0.631 & 0.026 \\
\hline sons & 0.965 & 0.959 & 0.455 & 0.035 \\
\hline family support & 0.951 & 1.377 & 0.227 & 0.049 \\
\hline gender ${ }^{\star}$ sons & 0.944 & 1.579 & 0.156 & 0.056 \\
\hline gender ${ }^{\star}$ family support & 0.971 & 0.807 & 0.566 & 0.029 \\
\hline sons ${ }^{\star}$ family support & 0.987 & 0.351 & 0.908 & 0.013 \\
\hline gender*sons ${ }^{\star}$ family support & 0.965 & 0.976 & 0.443 & 0.035 \\
\hline \multicolumn{5}{|c|}{ Dependent variables: DERS subscales } \\
\hline age (covariate) & $0.921^{*}$ & 2.287 & 0.038 & 0.079 \\
\hline working hour (covariate) & 0.982 & 0.487 & 0.817 & 0.018 \\
\hline \multicolumn{5}{|l|}{ Factors } \\
\hline gender & 0.961 & 1.082 & 0.375 & 0.039 \\
\hline sons & $0.909^{*}$ & 2.645 & 0.018 & 0.091 \\
\hline family support & $0.912^{*}$ & 2.565 & 0.021 & 0.088 \\
\hline gender ${ }^{\star}$ sons & $0.909^{*}$ & 2.651 & 0.018 & 0.091 \\
\hline gender ${ }^{\star}$ family support & 0.952 & 1.326 & 0.249 & 0.048 \\
\hline sons ${ }^{\star}$ family support & 0.948 & 1.450 & 0.199 & 0.052 \\
\hline gender ${ }^{*}$ sons ${ }^{\star}$ amily support & 0.957 & 1.203 & 0.308 & 0.043 \\
\hline
\end{tabular}

of these conflicts. Separate regressions were applied, each one using the different dimensions investigated for the WFCS (wfcs_tbwf: Time-Based Work Interference with Family; wfcs_tbfw: Time-Based Family Interference with Work; wfcs_sbwf: Strain-Based Work Interference with Family; wfcs_sbfw: Strain-Based Family Interference with Work; wfcs_bbwf: Behavioral-Based Work Interference with Family; wfcs_bbfw: Behavioral-Based Family Interference with Work). These regressions let us control for many of the factors that potentially influenced each dimensions of the work-family conflict. Indeed, these stepwise regressions are specifically useful in the selection of a subset of variables affecting the criterion variable; in this way, we might improve the model prediction by dropping the variance affected by estimating unnecessary variables, removing the feeblest correlated variables with the WFC dimensions. Indeed, at the end of this statistical procedure, we are left with the variables in the regression equation that best 
explain the distribution of each dimension of WFCS.

The initial selection of variables to embrace in these multiple regressions was based on the outcomes of previous correlation analyses. The preliminary analysis revealed the absence of collinearity issues.

In the Stepwise Multiple Regression Analyses the predictors were inserted in two blocks: the first block considered the socio demographic, familial and work related variables (age, gender, relational status, presence of sons, family support, working hours, variability of work schedule, night work, years of professional seniority, type of nurse activity); in the second block the six dimensions related to the emotion regulation (DERS) were inserted in the regression equation (DERS_No_Accept: Non-acceptance of emotional responses; ders_Goals: Difficulty engaging in Goal-directed behaviour; ders_Impulse: Impulse control difficulties; ders_Awareness: Lack of emotional awareness; ders_Strategies: Limited access to emotion regulation strategies; ders_Clarity: Lack of emotional clarity). The estimated $b$ and beta $(\beta)$ coefficients, their associated t-value, the significance and Variance Inflation Factors (VIF) are shown in Table 3.

Table 3. Multiple linear regressions (Method Stepwise).

\begin{tabular}{|c|c|c|c|c|c|c|c|c|}
\hline Dependent variable & Model & $\begin{array}{c}\text { Adj } R_{2} \\
\text { (ES) }\end{array}$ & Variables & B & Beta & $\mathrm{t}$ & $p$ & VIF \\
\hline \multirow[t]{2}{*}{ WFCS_TBWF } & 1 & $\begin{array}{c}0.027 \\
(3.238)\end{array}$ & WORKING HOURS PER DAY & 0.309 & 0.178 & 2.625 & 0.009 & 1.000 \\
\hline & 2 & $\begin{array}{c}0.057 \\
(3.187)\end{array}$ & $\begin{array}{l}\text { WORKING HOURS PER DAY } \\
\text { DERS_NO_ACCEPT }\end{array}$ & $\begin{array}{l}0.293 \\
0.117\end{array}$ & $\begin{array}{l}0.169 \\
0.186\end{array}$ & $\begin{array}{l}2.520 \\
2.783\end{array}$ & $\begin{array}{l}0.012 \\
0.006\end{array}$ & $\begin{array}{l}1.003 \\
1.003\end{array}$ \\
\hline WFCS_TBFW & 1 & $\begin{array}{c}0.020 \\
(2.631)\end{array}$ & DERS_IMPULSE & 0.091 & 0.156 & 2.283 & 0.023 & 1.000 \\
\hline \multirow[t]{3}{*}{ WFCS_SBWF } & 1 & $\begin{array}{c}0.017 \\
(3.054)\end{array}$ & FAMILY SUPPORT & -0.952 & -0.146 & -2.138 & 0.034 & 1.000 \\
\hline & 2 & $\begin{array}{c}0.089 \\
(2.940)\end{array}$ & FAMILY SUPPORT & -0.933 & -0.143 & -2.177 & 0.031 & 1.000 \\
\hline & & & DERS_IMPULSE & 0.186 & 0.275 & 4.190 & 0.0001 & 1.000 \\
\hline WFCS_SBFW & 1 & $\begin{array}{c}0.157 \\
(2.514)\end{array}$ & DERS_IMPULSE & 0.241 & 0.401 & 6.351 & 0.0001 & 1.000 \\
\hline \multirow[t]{5}{*}{ WFCS_BBWF } & 1 & $\begin{array}{c}0.023 \\
(2.685)\end{array}$ & WORKING HOURS PER DAY & 0.239 & 0.166 & 2.444 & 0.015 & 1.000 \\
\hline & 2 & 0.131 & WORKING HOURS PER DAY & 0.214 & 0.149 & 2.320 & 0.021 & 1.003 \\
\hline & 2 & $(2.532)$ & DERS_NO_ACCEPT & 0.174 & 0.335 & 5.209 & 0.0001 & 1.003 \\
\hline & & 0.150 & WORKING HOURS PER DAY & 0.242 & 0.168 & 2.630 & 0.009 & 1.019 \\
\hline & 3 & $(2.504)$ & $\begin{array}{l}\text { DERS_NO_ACCEPT } \\
\text { DERS_AWARENESS }\end{array}$ & $\begin{array}{l}0.165 \\
0.158\end{array}$ & $\begin{array}{l}0.316 \\
0.154\end{array}$ & $\begin{array}{l}4.934 \\
2.388\end{array}$ & $\begin{array}{c}0.0001 \\
0.018\end{array}$ & $\begin{array}{l}1.018 \\
1.030\end{array}$ \\
\hline \multirow[t]{2}{*}{ WFCS_BBFW } & 1 & $\begin{array}{c}0.030 \\
(2.728)\end{array}$ & VARIABILITY OF WORKING TIME & 1.201 & 0.187 & 2.762 & 0.006 & 1.000 \\
\hline & 2 & 0.121 & VARIABILITY OF WORKING TIME & 1.203 & 0.188 & 2.906 & 0.004 & 1.000 \\
\hline
\end{tabular}

Note: WFCS_TBWF: Time-Based Work Interference With Family; WFCS_TBFW: Time-Based Family Interference With Work; WFCS_SBWF: Strain-Based Work Interference With Family; WFCS_SBFW: Strain-Based Family Interference With Work; WFCS_BBWF: Behavioural-Based Work Interference With Family; WFCS_BBFW: Behavioural-Based Family Interference With Work; DERS_ NO_ACCEPT: Non-acceptance of emotional responses; DERS_GOALS: Difficulty engaging in Goal-directed behaviour; DERS_IMPULSE: Impulse control difficulties; DERS_AWARENESS: Lack of emotional awareness; DERS_STRATEGIES: Limited access to emotion regulation strategies; DERS_CLARITY: Lack of emotional clarity; VIF: Variance Inflation Factors. 
The results show that, initially, in relation to the subscale WFCS_TBWF (Time-Based Work Interference With Family), at the first step of regression, the effect of working hours per day accounted for $2 \%$ of the variance in criterion variable $\left(\beta=0.178 ; \mathrm{R}^{2}=0.027 ; \mathrm{SE}=3.238\right)$. This value at the second step raises to $5 \%$, after including the variance due to working hours per day $(\beta=0.169)$ and the significant effect of DERS_NO_ACCEPT (Non-acceptance of emotional responses) $(\beta=0.186)$. The total variance shared among these variables at the second step is low $\left(\mathrm{R}^{2}=0.057\right.$; $\left.\mathrm{SE}=3.187\right)$, showing that, among all investigated predictors, only these two predictors might be considered as risk factors related to the enhancement of the WFCS_TBWF.

Furthermore, the results of second regression highlighted a weak but significant relation between the WFCS_TBFW (Time-Based Family Interference with Work) and DERS_IMPULSE (Impulse control difficulties) $(\beta=0.156)$. The value of explained variance of criterion is about $2 \%\left(\mathrm{R}^{2}=0.020 ; \mathrm{SE}=2.631\right)$, highlighting that, among all predictors, only this variable of dysfunctional emotion regulation might be a risk factor, supporting the perception of higher levels of WFCS_TBWF.

Using the subscale of WFCS_SBWF as criterion variable (Strain-Based Work Interference with Family) we find that, at the first step, family support is the only significant protective effect $\left(\beta=-0.146 ; \mathrm{R}^{2}=0.017 ; \mathrm{SE}=3.054\right)$. At the second step, including the equation the DERS dimensions, we still highlight the significant protective effect of the family support $(\beta=-0.143)$ and a significant negative effect of DERS_IMPULSE (Impulse control difficulties) $(\beta=0.275)$ on the perception of Strain-Based Work Interference with Family. For this second step, we note the $8 \%$ variance of criterion variable $\left(\mathrm{R}^{2}=0.089 ; \mathrm{SE}=2.940\right)$.

The regression having the WFCS_SBFW (Strain-Based Family Interference with Work) as criterion variable explains about the $15 \%$ of variance $\left(\mathrm{R}^{2}=0.157\right.$; $\mathrm{SE}=2.514)$. For this dependent variable, only the significant effect of DERS_IMPULSE $(\beta=0.401)$ is highlighted, which might be considered as a risk factor in the WFCS_SBFW.

In relation to the criterion variable of WFCS_BBWF (Behavioral-Based Work Interference with Family) at the first step a significant effect is registered for working hours per day $(\beta=0.166)$, accounting for $2 \%$ of variance of the criterion variable $\left(\mathrm{R}^{2}=0.023 ; \mathrm{SE}=2.685\right)$. At the second step the DERS_NO_ACCEPT $(\beta$ $=0.335)$ is added in the equation with working hours per day $(\beta=0.149)$, which explains the almost $13 \%$ of variance $\left(\mathrm{R}^{2}=0.131 ; \mathrm{SE}=2.532\right)$. Finally, the third step of regression highlights the significant effect of three predictors (working hours per day $\beta=0.168$; DERS_NO_ACCEPT $\beta=0.316$; DERS_AWARENESS $\beta$ $=0.154)$, which might be considered as risk factors in the WFCS Behavioral-Based Work Interference with Family. At the final step of regression the explained variance corresponds to $15 \%\left(\mathrm{R}^{2}=0.150 ; \mathrm{SE}=2.504\right)$.

The last subscale WFCS_BBFW (Behavioral-Based Family Interference with Work) is related at the first step to the effect of variability of working time $\beta=$ 
0.187). At the second step the significant effect variability of working time ( $\beta=$ $0.188)$ and DERS_NO_ACCEPT $(\beta=0.307)$ is highlighted. The percentage of variance in the WFCS_BBFW explained by these risk factors is about $12 \%\left(\mathrm{R}^{2}=\right.$ 0.121; SE = 2.598).

Generally, we might observe that family support seems to exert a protective effect on the perception of WFCS_SBWF; on the other hand, the dysfunctional strategies of emotion regulation are likely to constitute potential risk factors in the perception of WF and FW conflicts. Specifically, among all ER dimensions, the difficulty in the impulse control, the lack of awareness and the no acceptation of emotional responses are highlighted as factors that are most significantly related to the perception of WF and of FW conflicts.

\section{Discussion}

This research aims to assess whether ER might affect the association among different antecedent variables and WFC, through an integrate research design approach. This topic is seldom investigated within the literature on nursing, as scholars focus mostly on the effects of some of the variables identified in our research, but fail to consider the ER as linking variable in the association of different predictors and the WFC. By contrast, we believe it is fundamental to assess seriously the topic, to delve into it using scientific canons while also taking into account the extensive knowledge about emotional demands in nursing and the ability of ER.

Through applying the MANCOVAs, we might highlight the absence of significant differences among the means in W-F-C and F-W-C, as well as for the DERS in relation to socio-demographic, familial and work related variables.

Indeed, our findings permit to observe that, although there are significant effects in the multivariate level for the DERS, any statistically significant effects are highlighted in the univariate effects. Also, in relation to the WFCS, there are not significant differences among the means in relation to the factors examined (gender, the presence of sons, the presence of family support). These findings were obtained by controlling the effects of the covariates age and working hours. As regards gender, our findings are in line with the research sustaining that WFC is perceived similarly by women and by men [79]. About familial variables, we did not find differences in the means in relation to their effect; other scholars outlined, for instance, that the lack of assistance with housework and spending much time in housework and in child care seem associated with an increasing of WFC [28].

Finally, our sample seems homogeneous in relation to the dimensions investigated of W-F-C, F-W-C and ER. Specifically, about the ER dimensions, our findings are consistent with the results obtained by Giromini et al. [76] in the Italian validation of the DERS, which prove the absence of significant differences in the dimensions' scores for male and female. Furthermore, regarding the differences about the two WFC directions, in our sample we observed that the le- 
vels of the two directions are similar. These results are not in line with several researches that sustained the prevalence of $\mathrm{W}-\mathrm{F}-\mathrm{C}$ also in nursing then $\mathrm{F}-\mathrm{W}-\mathrm{C}$ [7] [15].

The findings of regressions highlighted that only some dimensions related to the work and familial organization might affect the perception of $W-F-C$ and $F-W$ - $C$. These outcomes are consistent with the majority of the research carried out, which outlined that the two WFC directions are influenced by different antecedents. Specifically, it is interesting to observe that among socio-demographic and work-related variables, working day hours significantly influenced WFCS_TBWF (Time-Based Work Interference with Family) and shift work affected WFCS_BBWF (Behavioral-Based Work Interference with Family). These findings not only confirmed the importance of job demands to evoke WFC, but also the specific importance of the working hours and their interference with the time available for family and leisure [23] [24]. The longer work hours may increase WFC simply by making less familial time available to nurses, as has been argued in relation to other employees [80]. In nursing, in addition to working hours, shiftwork remains an important antecedent of WFC [30] [31] as it is a job demand situation that can cause problems in work and family domains.

Introducing DERS dimensions, we observed that, during other working day hours, significant effects were of DERS_Difficulty to accept emotions on WFCS_TBWF; for WFCS_BBWF the effect of shift work keeps with the introduction of DERS_NO_ACCEPT and DERS_Lack of emotional awareness. Only DERS_Impulse control difficulties seem to have an effect on WFCS_Time-Based Family Interference with Work and on WFCS Strain-Based Family Interference with Work; any other variable affects these last dimensions. Our results suggest that focusing on specific strategies could enhance the understanding of how nurses can manage WFC. This is in line with the research that found a curvilinear effect for hours worked on WFC and other outcomes, underlining that work demands did not lead directly to negative effects, but this association was influenced by some mediator factors [81]. In particular, we found that DERS, such as the difficulty to accept emotions, lack of emotional awareness and impulse to control difficulties seems to increase the negative effects of on WFC. This confirms not only the importance that nursing literature attributes to emotions and their adequate expression, but mainly that the necessity of nurses' professional face or mask, consisting in emotional suppression of personal feelings and emotions, may be difficult and tiring for nurses. The two ERS, difficulty to accept emotions and lack of emotional awareness, represent the difficulty of nurses to take into account their affective needs and express their escape from emotional situations. Some scholars outlined that emotional charge that nurses lived at work and the necessity of emotional control can create a state of emotional dissonance and inauthenticity in nurses [82] [83], that if they are frequent and lasting for a long time they can be stressful and, therefore, can negatively affect the providing optimal nursing care and nurse-patient relationship [51] [82]. 
This emotional dissonance lived by nurses has been associated with WFC [26]. So, in line with the ability to manage one's own emotions expressed by the construct of ER, nurses should recognize their emotions and how, when and where to express them [47]. Our results confirmed that the emotional suppression (iper-control of emotions) can be a dis-regulatory emotional way to live emotions [84]. In addition, the difficulty to accept emotions and lack of emotional awareness cannot be considered as genuine behaviors, as these may negatively influence interpersonal relations and, consequently, workers' well-being and performance [60]. Still, these two ERS required high cognitive control resources and that has been observed as a possible explanation of the more little efficacy of surface acting that deep acting [60], such as emotional acceptance requiring a poor effort in the emotional regulation [61].

In general, our results seem to confirm, also for WFC, the role of maladaptive ERS (such as emotional avoidance and suppression) on harmful outcomes, which has been recognized by many scholars and which concerns both lower social functioning [67] [68] and mental disorders [71].

Considering the two directions of WFC, our results permit to note the role of different ER strategies. So, while the difficulty to accept emotions and lack of emotional awareness seem to increase the effect of workings day hours on Work-to-Family conflict, the impulse to control difficulties increased the perception of the interference of family issues on achieving work goals (W-F-C). In particular, we found that the difficulty of impulse control (DERS_IMPULSE) influenced the family interference with work based on the time and on the strain. Therefore, when nurses have difficulty to control their impulse, they express a high perception of the burden of familial requests, also as regards the time that they devote to the family. Therefore, our results permit to sustain that the association between familial demands and WFC observed in literature [34] [35] can be increased by the presence of the difficulty of nurses to control their impulse.

On the other hand, the presence of family support might reduce the perception of FWC. In fact familial support seems to have a protective effect on WFCS_SBWF (Strain-Based Work Interference with Family) and it also had a negative association with total score of WFC scale, so when familial support increased, WFC decreased. This result confirms the role of protective factor played by the social support, and in our case familial support, considered active response to work-family roles interference [27] [85].

\section{Limitations}

Like all research, this study has several limitations. First, we adopted a cross-sectional research design that did not permit to draw cause-and-effect inferences for our findings. Therefore, it could be useful in future research to use longitudinal designs, which are clearly relevant in work-family research [86] and our research is no exception. Our study is also limited by the use of a convenience sample of individuals; therefore, we did not generalize our findings. Also, 
we did not analyze some differential factors regarding wards and organization types, full and part-time working, inconvenient work schedules as weekend work, variable/flexible working time, prolonged duty periods, considered as important antecedents of WFC in nursing [29] [30] [31] [32].

Besides, we considered emotional dis-regulation strategies measured by DERS. It could also be useful to analyze some good emotional regulation strategies and their positive role to balance WF interface, such as emotional awareness. Individuals who are able to regulate effectively their emotions might report less WFC. This might further integrate existing researches that tend to examine a direct association between objective characteristics of the work and the family environment, as well as WFC [87]. The findings, according to which some ERS increased the effects of some antecedents differently than for W-F-C and F-W-C, suggest the importance of taking into account the domain in which the WFC is experienced to understand more fully work-family interactions.

Moreover, our study is limited to the WFC outcomes, because we did not consider the effects of WFC on nurses' health and well-being, their job performance and job satisfaction or their quality of familial life, as investigated by the majority of literature in this field. Then, we can extend further our results to include some outcomes of WFC. We also neglected some key work related to protective factors, such as work social support, which can buffer the effects of WFC [41] and the emotional support by partners that can help people cope with WFC [44].

\section{Conclusions and Future Research}

Notwithstanding its limitations, the present study makes several important contributions to theory and research. Most notably, we extend research about the effects of work and family antecedents on WFC through introducing ER dimension. Therefore, we also highlighted an important variable regarding individual differences, which should be considered in future research on the emotional abilities in work and family interference. It could be of interesting to take into account the association between specific emotional demands in nursing and the various ER strategies in order to observe what are more efficacious to balance work and family domains. In our research, we have considered only some familiar variables, but it would be interesting to extend the assessment also to other relational dimensions (such as job and familial satisfaction and couple affectivity) that might influence the skills and modalities of emotional regulation of people, consequently also their ability to balance work and familial demands.

The current findings also provide important practical implications. Our results permit to sustain that the adopted and implemented work-family policies in health organization might not provide the complete solution to the problem, with respect to WF interference. In fact, our results advance the literature by indicating that ER may better handle this conflict. An integration of work-family programs and an ER strategies education can better attain the desired balance 
[88]. In particular, more policies should be created to take special care of WFC in nursing and schools, for example by providing counseling services to help nurses improve their emotion management skills in order to cope with WFC. Moreover, this study demonstrates that some ERS increased the effects of some antecedents on WFC, thus showing the potential value of ER for the training and development of nurses in teaching their profession. An organization might help nurses to learn efficacy ERS through training, critical support and other tactics in order to decrease the negative influence of WFC. Training programs might help nurses both understand the possible deleterious effects of some ERS in work and family domains, and build good emotional regulation skills so as to cope with emotional work and with family demands. Regarding the nursing practice and education, it would be desirable not only in order to implement prevention programs to improve the emotional regulation skills of nurses, but also to increase the attention of the scholars toward the assessment of their efficacy.

\section{Conflicts of Interest}

None declared.

\section{Ethical Approval}

We have obtained approval by the responsible of the Health Care Structure.

\section{References}

[1] Duffield, C., Roche, M., O'Brien-Pallas, L., Catling-Paull, C. and King, M. (2009) Staff Satisfaction and Retention and the Role of the Nursing Unit Manager. Collegian, 16, 11-17. https://doi.org/10.1016/j.colegn.2008.12.004

[2] Carter, M.R. and Tourangeau, A.E. (2012) Staying in Nursing: What Factors Determine Whether Nurses Intend to Remain Employed? Journal of Advanced Nursing, 68, 1589-1600. https://doi.org/10.1111/j.1365-2648.2012.05973.x

[3] Khamisa, N., Peltzer, K. and Oldenburg, B. (2013) Burnout in Relation to Specific Contributing Factors and Health Outcomes among Nurses: A Systematic Review. International Journal of Environmental Research and Public Health, 10, 2214-2240. https://doi.org/10.3390/ijerph10062214

[4] Glazer, S. and Gyurak, A. (2008) Sources of Occupational Stress among Nurses in Five Countries. International Journal of Intercultural Relations, 32, 49-66. https://doi.org/10.1016/j.ijintrel.2007.10.003

[5] Schmidt, K.H. and Diestel, S. (2014) Are Emotional Labour Strategies by Nurses Associated with Psychological Costs? A Cross-Sectional Survey. International Journal of Nursing Studies, 51, 1450-1461. https://doi.org/10.1016/j.ijnurstu.2014.03.003

[6] Mihelič, K.K. (2014) Work-Family Conflict: A Review of Antecedents and Outcomes. International Journal of Management \& Information Systems, 18, 15-26.

[7] Grzywacz, J.G., Frone, M.R., Brewer, C.S. and Kovner, C.T. (2006) Quantifying Work-Family Conflict among Registered Nurses. Research in Nursing and Health, 29, 414-426. https://doi.org/10.1002/nur.20133

[8] Yanchus, N.J., Eby, L.T., Lance, C.E. and Drollinger, S. (2010) The Impact of Emo- 
tional Labor on Work-Family Outcomes. Journal of Vocational Behavior, 76, 105-117. https://doi.org/10.1016/j.jvb.2009.05.001

[9] Lenaghan, J., Buda, R. and Eisner, A. (2007) An Examination of the Role of Emotional Intelligence in Work and Family Conflict. Journal of Managerial Issues, 19, 76-94.

[10] Augusto Landa, J.M., Lopez-Zafra, E., del Carmen Aguilar-Luzón M. and de Ugarte, M.F.S. (2009) Predictive Validity of Perceived Emotional Intelligence on Nursing Students' Self-Concept. Nurse Education Today, 29, 801-808. https://doi.org/10.1016/j.nedt.2009.04.004

[11] Beauvais, A.M., Brady, N., O’Shea, E.R. and Griffin, M.T.Q. (2011) Emotional Intelligence and Nursing Performance among Nursing Students. Nurse Education Today, 31, 396-401. https://doi.org/10.1016/j.nedt.2010.07.013

[12] Money, J.B. and Peter, A.J (2014) Impact of Emotional Intelligence on Work Life Balance-A Global Perspective. Journal of Exclusive Management Science, 3, 1-8.

[13] Edwards, J.R. and Rothbard, N. (2000) Mechanisms Linking Work and Family: Clarifying the Relationship between Work and Family Constructs Work Home. Academy of Management Review, 25, 178-199.

https://doi.org/10.5465/amr.2000.2791609

[14] Greenhaus, J.H. and Beutell, N.J. (1985) Sources of Conflict between Work and Family Roles. Academy of Management Review, 10, 76-88.

https://doi.org/10.5465/amr.1985.4277352

[15] Gandi, J.C. (2011) Nurse's Roles and the Mediating Effects of Stress on Job Performance in Low and Developing Economies. Psychology, 2, 323-330.

https://doi.org/10.4236/psych.2011.24051

[16] Fox, M.F., Fonseca, C. and Bao, J. (2011) Work and Family Conflict in Academic Science: Patterns and Predictors among Women and Men in Research Universities. Social Studies of Science, 41, 715-735. https://doi.org/10.1177/0306312711417730

[17] Kinnunen, U., Geurts, S. and Mauno, S. (2004) Work-to-Family Conflict and Its Relationship with Satisfaction and Well-Being: A One-Year Longitudinal Study on Gender Differences. Work \& Stress, 18, 1-22. https://doi.org/10.1080/02678370410001682005

[18] Keepnews, D.M., Brewer, C.S., Kovner, C.T. and Shin, J.H. (2010) Generational Differences among Newly Licensed Registered Nurses. Nursing Outlook, 58, 155-163. https://doi.org/10.1016/j.outlook.2009.11.001

[19] Yamaguchi, Y., Inoue, T., Harada, H. and Oike, M. (2016) Job Control, Work-Family Balance and Nurses' Intention to Leave Their Profession and Organization: A Comparative Cross-Sectional Survey. International Journal of Nursing Studies, 64, 52-62. https://doi.org/10.1016/j.ijnurstu.2016.09.003

[20] Sharma, J., Dhar, R.L. and Tyagi, A. (2016) Stress as a Mediator between Work-Family Conflict and Psychological Health among the Nursing Staff: Moderating Role of Emotional Intelligence. Applied Nursing Research, 30, 268-275. https://doi.org/10.1016/j.apnr.2015.01.010

[21] Kim, S.-S., Okechukwu, C.A., Buxton, O.M., Dennerlein, J.T., Boden, L.I., Hashimoto, D.M. and Sorensen, G. (2013) Association between Work-Family Conflict and Musculoskeletal Pain among Hospital Patient Care Workers. American Journal of Industrial Medicine, 56, 488-495. https://doi.org/10.1002/ajim.22120

[22] Wang, Y., Chang, Y., Fu, J. and Wang, L. (2012) Work-Family Conflict and Burnout among Chinese Female Nurses: The Mediating Effect of Psychological Capital. BMC Public Health, 12, 1-8. https://doi.org/10.1186/1471-2458-12-915 
[23] Crompton, R. and Lyonette, C. (2006) Work-Life "Balance" in Europe. Acta Sociologica, 49, 379-393. https://doi.org/10.1177/0001699306071680

[24] van der Lippe, T., Jager, A. and Kops, Y. (2006) Combination Pressure. Acta Sociologica, 49, 303-319. https://doi.org/10.1177/0001699306067711

[25] Adkins, C.L. and Premeaux, S.F. (2012) Spending Time: The Impact of Hours Worked on Work-Family Conflict. Journal of Vocational Behavior, 80, 380-389. https://doi.org/10.1016/j.jvb.2011.09.003

[26] Ghislieri, C., Gatti, P., Molino, M. and Cortese, C.G. (2017) Work-Family Conflict and Enrichment in Nurses: Between Job Demands, Perceived Organizational Support and Work-Family Backlash. Journal of Nursing Management, 25, 65-75. https://doi.org/10.1111/jonm.12442

[27] Lagerström, M., Josephson, M., Arsalani, N. and Fallahi-Khoshknab, M. (2010) Striving for Balance between Family and Work Demands among Iranian Nurses. Nursing Science Quarterly, 23, 166-172. https://doi.org/10.1177/0894318410362543

[28] Takeuchi, T. and Yamazaki, Y. (2010) Relationship between Work-Family Conflict and a Sense of Coherence among Japanese Registered Nurses. Japan Journal of Nursing Science, 7, 158-168. https://doi.org/10.1111/j.1742-7924.2010.00154.x

[29] Abrahamsen, B., Holte, K.A. and Laine, M. (2012) Work-Family Interference: Nurses in Norway and Finland. Professions \& Professionalism, 2, 60-74. https://doi.org/10.7577/pp.v2i1.19

[30] Costa, G. (2010) Shift Work and Health: Current Problems and Preventive Actions. Safety and Health at Work, 1, 112-123. https://doi.org/10.5491/SHAW.2010.1.2.112

[31] Kunst, J.R., Løset, G.K., Hosøy, D., Bjorvatn, B., Moen, B.E., Magerøy, N. and Pallesen, S. (2014) The Relationship between Shift Work Schedules and Spillover in a Sample of Nurses. International Journal of Occupational Safety and Ergonomics, 20, 139-147. https://doi.org/10.1080/10803548.2014.11077030

[32] Camerino, D., Sandri, M., Sartori, S., Conway, P.M., Campanini, P. and Costa, G. (2010) Shiftwork, Work-Family Conflict among Italian Nurses and Preventive Efficacy. Chronobiology International, 27, 1105-1123. https://doi.org/10.3109/07420528.2010.490072

[33] Schulz, M.S., Cowan, P.A., Pape Cowan, C. and Brennan, R.T. (2004) Coming Home Upset: Gender, Marital Satisfaction, and the Daily Spillover of Workday Experience Into Couple Interactions. Journal of Family Psychology, 18, 250-263. https://doi.org/10.1037/0893-3200.18.1.250

[34] Cinamon, R.G, Weisel, A. and Tzuk, K. (2007) Work-Family Conflict within the Family: Crossover Effects, Perceived Parent-Child Interaction Quality, Parental Self-Efficacy, and Life Role Attributions. Journal of Career Development, 34, 79-100. https://doi.org/10.1177/0894845307304066

[35] Vieira, J.M., Ávila, M. and Matos, P.M. (2012) Attachment and Parenting: The Mediating Role of Work-Family Balance in Portuguese Parents of Preschool Children. Family Relations, 61, 31-50. https://doi.org/10.1111/j.1741-3729.2011.00680.x

[36] Bakker, A.B. and Heuven, E. (2006) Emotional Dissonance, Burnout, and In-Role Performance among Nurses and Police Officers. International Journal of Stress Management, 13, 423-440. https://doi.org/10.1037/1072-5245.13.4.423

[37] Cortese, C.G., Colombo, L. and Ghislieri, C. (2010) Determinants of Nurses' Job Satisfaction: The Role of Work-Family Conflict, Job Demand, Emotional Charge and Social Support. Journal of Nursing Management, 18, 35-43. https://doi.org/10.1111/j.1365-2834.2009.01064.x 
[38] Allen, T.D., Johnson, R.C., Saboe, K.N., Cho, E., Dumani, S. and Evans, S. (2012) Dispositional Variables and Work-Family Conflict: A Meta-Analysis. Journal of Vocational Behavior, 80, 17-26. https://doi.org/10.1016/j.jvb.2011.04.004

[39] Karatepe, O.M. and Karadas, G. (2014) The Effect of Psychological Capital on Conflicts in the Work-Family Interface, Turnover and Absence Intentions. International Journal of Hospitality Management, 43, 132-143. https://doi.org/10.1016/j.ijhm.2014.09.005

[40] Haddock, S.A., Zimmerman, T.S., Ziemba, S.J. and Lyness, K.P. (2006) Practices of Dual Earner Couples Successfully Balancing Work and Family. Journal of Family and Economic Issues, 27, 207-234. https://doi.org/10.1007/s10834-006-9014-y

[41] Karatepe, O.M. (2010) The Effect of Positive and Negative Work-Family Interaction on Exhaustion. International Journal of Contemporary Hospitality Management, 22, 836-856. https://doi.org/10.1108/09596111011063115

[42] Roche, M. and Haar, J. (2010) Work-Family Interface Predicting Needs Satisfaction: The Benefits for Senior Management. Journal of Social \& Behavioural Research in Business, 1, 12-23. http://www.ejsbrb.org

[43] Yildirim, D. and Aycan, Z. (2008) Nurses' Work Demands and Work-Family Conflict: A Questionnaire Survey. International Journal of Nursing Studies, 45, 1366-1378. https://doi.org/10.1016/j.ijnurstu.2007.10.010

[44] Selvarajan, T.T., Cloninger, P.A. and Singh, B. (2013) Social Support and Work-Family Conflict: A Test of an Indirect Effects Model. Journal of Vocational Behavior, 83, 486-499. https://doi.org/10.1016/j.jvb.2013.07.004

[45] Rogers, S.J. and May, D.C. (2003) Spillover between Marital Quality and Job Satisfaction: Long-Term Patterns and Gender Differences. Journal of Marriage and Family, 65, 482-495. https://doi.org/10.1111/j.1741-3737.2003.00482.x

[46] Akerjordet, K. and Severinsson, E. (2007) Emotional Intelligence: A Review of the Literature with Specific Focus on Empirical and Epistemological Perspectives. Journal of Clinical Nursing, 16, 1405-1416. https://doi.org/10.1111/j.1365-2702.2006.01749.x

[47] Gross, J.J. (2014) Emotion Regulation: Conceptual and Empirical Foundations. In: Gross, J.J., Ed., Handbook of Emotion Regulation, 2nd Edition, Guilford, New York, 3-20.

[48] Hochschild, A.R. (1979) Emotion Work, Feeling Rules, and Social Structure. American Journal of Sociology, 85, 551-575. https://doi.org/10.1086/227049

[49] Hochshild, A.R. (1983) The Managed Heart: Commercialization of Human Feeling. University of California Press, Berkeley.

[50] Lawrence, S.A., Troth, A.C., Jordan, P.J. and Collins, A.L. (2011) A Review of Emotion Regulation and Development of a Framework for Emotion Regulation in the Workplace. Research in Occupational Stress and Well Being, 9, 197-263. https://doi.org/10.1108/S1479-3555(2011)0000009010

[51] Cecil, P. and Glass, N. (2014) An Exploration of Emotional Protection and Regulation in Nurse-Patient Interactions: The Role of the Professional Face and the Emotional Mirror. Collegian, 22, 377-385. https://doi.org/10.1016/j.colegn.2014.06.002

[52] Diefendorff, J.M., Croyle, M.H. and Gosserand, R.H. (2005) The Dimensionality and Antecedents of Emotional Labor Strategies. Journal of Vocational Behavior, 66, 339-357. https://doi.org/10.1016/j.jvb.2004.02.001

[53] Gray, B. (2009) The Emotional Labour of Nursing-Defining and Managing Emotions in Nursing Work. Nurse Education Today, 29, 168-175.

https://doi.org/10.1016/j.nedt.2008.08.003 
[54] Gratz, K.L. and Roemer, L. (2004) Multidimensional Assessment of Emotion Regulation and Dysregulation. Journal of Psychopathology and Behavioral Assessment, 26, 41-54. https://doi.org/10.1023/B:JOBA.0000007455.08539.94

[55] Kashdan, T.B. (2007) New Developments in Emotion Regulation with an Emphasis on the Positive Spectrum of Human Functioning. Journal of Happiness Studies, 8, 303-310. https://doi.org/10.1007/s10902-006-9013-6

[56] Tugade, M.M. and Fredrickson, B.L. (2007) Regulation of Positive Emotions: Emotion Regulation Strategies That Promote Resilience. Journal of Happiness Studies, 8, 311-333. https://doi.org/10.1007/s10902-006-9015-4

[57] Gross, J.J. (1998) Antecedent- and Response-Focused Emotion Regulation: Divergent Consequences for Experience, Expression, and Physiology. Journal of Personality and Social Psychology, 74, 224-237.

https://doi.org/10.1037/0022-3514.74.1.224

[58] Gross, J.J. (2002) Emotion Regulation: Affective, Cognitive, and Social Consequences. Psychophysiology, 39, S0048577201393198. https://doi.org/10.1017/S0048577201393198

[59] Hülsheger, U.R. and Schewe, A.F. (2011) On the Costs and Benefits of Emotional Labor: A Meta-Analysis of Three Decades of Research. Journal of Occupational Health Psychology, 16, 361-389. https://doi.org/10.1037/a0022876

[60] Holman, D., Martinez-Iñigo, D. and Totterdell, P. (2008) Emotional Labour, Well-Being and Performance. In: Cartwright, S. and Cooper, C.L., Eds., The Oxford Handbook of Organizational Well Being, Oxford University Press, Oxford, 331-355.

[61] Biron, M. and van Veldhoven, M. (2012) Emotional Labour in Service Work: Psychological Flexibility and Emotion Regulation. Human Relations, 65, 1259-1282. https://doi.org/10.1177/0018726712447832

[62] Judge, T.A., Woolf, E.F. and Hurst, C. (2009) Is Emotional Labour More Difficult for Some than for Others? A Multilevel, Experience-Sampling Study. Personnel Psychology, 62, 57-88. https://doi.org/10.1111/j.1744-6570.2008.01129.x

[63] Bonanno, G.A., Papa, A., Lalande, K., Westphal, M. and Coifman, K. (2004) The Importance of Being Flexible: The Agility to both Enhance and Suppress Emotional Expression Predicts Long-Term Adjustment. Psychological Science, 15, 482-487. https://doi.org/10.1111/j.0956-7976.2004.00705.x

[64] Paivio, S.C. and Greenberg, L.S. (2001) Introduction: Treating Emotion Regulation Problems. Journal of Clinical Psychology, 57, 153-155. https://doi.org/10.1002/1097-4679(200102)57:2<153::AID-JCLP2>3.0.CO;2-F

[65] Oliver, M.N.I. and Simons, J.S. (2004) The Affective Lability Scales: Development of a Short-Form Measure. Personality and Individual Differences, 37, 1279-1288. https://doi.org/10.1016/j.paid.2003.12.013

[66] Thompson, R.A. (2011) Methods and Measures in Developmental Emotions Research: Some Assembly Required. Journal of Experimental Child Psychology, 110, 275-285. https://doi.org/10.1016/j.jecp.2011.04.007

[67] English, T., John, O.P., Srivastava, S. and Gross, J.J. (2012) Emotion Regulation and Peer-Rated Social Functioning: A 4-Year Longitudinal Study. Journal of Research in Personality, 46, 780-784. https://doi.org/10.1016/j.jrp.2012.09.006

[68] English, T. and John, O.P. (2013) Understanding the Social Effects of Emotion Regulation: The Mediating Role of Authenticity for Individual Differences in Suppression. Emotion, 13, 314-329. https://doi.org/10.1037/a0029847

[69] Henry, J.D., Rendell, P.G., Green, M.J., McDonald, S. and O’Donnell, M. (2008) 
Emotion Regulation in Schizophrenia: Affective, Social, and Clinical Correlates of Suppression and Reappraisal. Journal of Abnormal Psychology, 117, 473-478. https://doi.org/10.1037/0021-843X.117.2.473

[70] Liverant, G.I., Brown, T.A., Barlow, D.H. and Roemer, L. (2008) Emotion Regulation in Unipolar Depression: The Effects of Acceptance and Suppression of Subjective Emotional Experience on the Intensity and Duration of Sadness and Negative Affect. Behaviour Research and Therapy, 46, 1201-1209. https://doi.org/10.1016/j.brat.2008.08.001

[71] Nolen-Hoeksema, S., Wisco, B.E. and Lyubomirsky, S. (2008) Rethinking Rumination. Perspectives on Psychological Science, 3, 400-424. https://doi.org/10.1111/j.1745-6924.2008.00088.x

[72] Barrett, L.F. and Bliss-Moreau, E. (2009) She's Emotional. He's Having a Bad Day: Attributional Explanations for Emotion Stereotypes. Emotion, 9, 649-658. https://doi.org/10.1037/a0016821

[73] Nolen-Hoeksema, S. (2012). Emotion Regulation and Psychopathology: The Role of Gender. Annual Review of Clinical Psychology, 8, 161-187. https://doi.org/10.1146/annurev-clinpsy-032511-143109

[74] Bender, P.K., Reinholdt-Dunne, M.L., Esbjørn, B.H. and Pons, F. (2012) Emotion Dysregulation and Anxiety in Children and Adolescents: Gender Differences. Personality and Individual Differences, 53, 284-288. https://doi.org/10.1016/j.paid.2012.03.027

[75] Lazarus, R.S. and Folkman, S. (1984) Stress, Appraisal, and Coping. Springer, New York.

[76] Giromini, L., Velotti, P., De Campora, G., Bonalume, L. and Zavattini, C. (2012) Cultural Adaptation of the Difficulties in Emotion Regulation Scale: Reliability and Validity of an Italian Version. Journal of Clinical Psychology, 68, 989-1007. https://doi.org/10.1002/jclp.21876

[77] Carlson, D.S., Kacmar, K.M. and Williams, L.J. (2000) Construction and Initial Validation of a Multidimensional Measure of Work-Family Conflict. Journal of Vocational Behavior, 56, 249-276. https://doi.org/10.1006/jvbe.1999.1713

[78] Loscalzo, Y., Raffagnino, R., Gonnelli, C. and Giannini, M. (unpublished) Work-Family Conflict Scale: Psychometric Properties of the Italian Version.

[79] Byron, K. (2005) A Meta-Analytic Review of Work-Family Conflict and Its Antecedents. Journal of Vocational Behavior, 67, 169-198. https://doi.org/10.1016/j.jvb.2004.08.009

[80] Di Renzo, M.S., Greenhaus, J.H. and Weer, C.H. (2011) Job Level, Demands, and Resources as Antecedents of Work-Family Conflict. Journal of Vocational Behavior, 78, 305-314. https://doi.org/10.1016/j.jvb.2010.10.002

[81] Ng, T.W.H. and Feldman, D.C. (2008) Long Work Hours: A Social Identity Perspective on Meta-Analysis Data. Journal of Organizational Behavior, 29, 853-880. https://doi.org/10.1002/job.536

[82] Hayward, R.M. and Tuckey, M.R. (2011) Emotions in Uniform: How Nurses Regulate Emotion at Work via Emotional Boundaries. Human Relations, 64, 1501-1523. https://doi.org/10.1177/0018726711419539

[83] Van Den Tooren, M. and De Jonge, J. (2008) Managing Job Stress in Nursing: What Kind of Resources Do We Need? Journal of Advanced Nursing, 63, 75-84. https://doi.org/10.1111/j.1365-2648.2008.04657.x

[84] Roberton, T., Daffern, M. and Bucks, R.S. (2012) Emotion Regulation and Aggres- 
sion. Aggression and Violent Behavior, 17, 72-82.

https://doi.org/10.1016/j.avb.2011.09.006

[85] Aycan, Z. and Eskin, M. (2005) Relative Contributions of Childcare, Spousal Support, and Organizational Support in Reducing Work-Family Conflict for Men and Women: The Case of Turkey. Sex Roles, 53, 453-471.

https://doi.org/10.1007/s11199-005-7134-8

[86] Casper, W.J., Bordeaux, C., Eby, L.T., Lockwood, A. and Lambert, D. (2007) A Review of Research Methods in IO/OB Work-Family Research. Journal of Applied Psychology, 92, 28-43. https://doi.org/10.1037/0021-9010.92.1.28

[87] Eby, L.T., Casper, W.J., Lockwood, A., Bordeaux, C. and Brinley, A. (2005) Work and Family Research in IO/OB: Content Analysis and Review of the Literature (1980-2002). Journal of Vocational Behavior, 66, 124-197.

https://doi.org/10.1016/j.jvb.2003.11.003

[88] Gonnelli, C., Raffagnino, R. and Puddu, L. (2016) The Emotional Regulation in Nursing Work: An Integrative Literature Review and Some Proposals for Its Implementation in Educational Programs. IOSR Journal of Nursing and Health Science, 5, 43-49. 